Voix et Images

voixetimages

\title{
Bibliographie de Suzanne Jacob
}

\section{Sylvie Lamarre et Martin Poirier}

Volume 21, numéro 2 (62), hiver 1996

Suzanne Jacob

URI : https://id.erudit.org/iderudit/201240ar

DOI : https://doi.org/10.7202/201240ar

Aller au sommaire du numéro

Éditeur(s)

Université du Québec à Montréal

ISSN

0318-9201 (imprimé)

1705-933X (numérique)

Découvrir la revue

Citer ce document

Lamarre, S. \& Poirier, M. (1996). Bibliographie de Suzanne Jacob. Voix et Images, 21(2), 285-298. https://doi.org/10.7202/201240ar d'utilisation que vous pouvez consulter en ligne.

https://apropos.erudit.org/fr/usagers/politique-dutilisation/ 


\title{
Bibliographie de Suzanne Jacob*
}

\author{
Sylvie Lamarre, Université du Québec à Montréal \\ et Martin Poirier, Université McGill
}

\section{CEUVRES}

\subsection{Volumes}

Flore Cocon [roman], Montréal, Parti pris, coll. "Sic", 1978, 124 p.; Parti pris, coll. "Paroles", 1981, et l'Hexagone, coll. " Fictions", 1990.

La Survie [nouvelles], Montréal, Le Biocreux, 1979, 140 p.; avec préface de Guy Cloutier, Montréal, BQ, coll. "Littérature ", 1989, 111 p.; traduit par Susanna Finnell, Life, After All, Vancouver, Press Gang Publishers, 1989.

Poèmes 1. Gémellaires. Le Chemin de Damas [poèmes], Montréal, Le Biocreux, coll. "Poésie 1", 1980, 72 p.

Laura Laur [roman], Paris, Seuil, 1983, 180 p.

La Passion selon Galatée [roman], Paris, Seuil, 1986, 240 p.

Les Aventures de Pomme Douly [nouvelles], Montréal, Boréal Express, 1988, 133 p.

Maude [récit], Montréal, La Nouvelle Barre du jour, coll. "Liberté grande", 1988, $113 \mathrm{p}$.

Plages du Maine [récit accompagné d'une illustration de l'auteure], Montréal, La Nouvelle Barre du jour, 1989, 45 p.; traduit par Susanna Finnell, A Beach in Maine, Montréal, Guernica, 1993.

Filandere cantabile [poème avec disque compact], avec la collaboration de International Imaginaire Manifesto, Marc Moreau et Marion Moreau, Paris, Marval, 1990, n. p.

L'Obéissance [roman], Paris, Seuil, 1991, 249 p. ; Montréal, Boréal Compact, 1993.

\subsection{Poèmes, textes et extraits}

\section{I.2.1. Parus dans des ouvrages collectifs}

Crapauds et autres animaux [en collaboration], Montréal, La Courte Échelle, 1981, $12 \mathrm{p}$.

- Nous tenons à remercier Suzanne Jacob, Lucie Joubert et Lori Saint-Martin pour leur précieuse collaboration à la réalisation de cette bibliographie. 
"Ex-voto/anathème" [œuvre in situ de Karen Pick visitée par Suzanne Jacob], Mirabile visu. La photographie 150 ans après, Montréal, les Centres d'artistes de Québec, 1990, p. 25.

"Le voyage à Victoria ", Enfances et jeunesses, Montréal, Les entreprises RadioCanada, 1990, p. 144-150.

\subsubsection{Parus dans des périodiques}

"Telles", Possibles, vol. IV, no 1, automine 1979, p. 93-100.

"Exergue" suivi de "Elle", La Nouvelle Barre du jour, n 82, octobre 1979, p. 6-11.

"La chaise haute ", La Nouvelle Barre du jour, no 87, février 1980, p. 48-60.

"Autoportrait: Suzanne Jacob", Québec français, n 38, mai 1980, p. 70-71.

"Wille", Liberté, no 129, mai-juin 1980, p. 41-49.

"Préface ", Biosphère, vol. I, no 1, automne 1980, p. 13-14.

"Pour une pratique de l'ambiguité ", Possibles, vol. V, $n^{\text {os }}$ 3-4: "Les nouvelles stratégies culturelles", 1981, p. 45-49.

"La femme assise ", La Nouvelle Barre du jour, n 112: "La complicité", mars 1982, p. 63-72.

"Le terrain ", La Nouvelle Barre du jour, no 132, novembre 1983, p. 47-53.

"Je veux avoir un futur...", La Nouvelle Barre du jour, no 140: "Sortie/exit ", juin 1984 , p. $77-78$.

"L'éternité et la sauce tomate ", La Vie en rose, n 18: "Histoires d'amour et d'eau saléen, juillet-août 1984, p. 31-32.

"Les calmars", Possibles, vol. X, n० 1, automne 1985, p. 37-44.

"Laisse, je dis, laisse", Trois, vol. I, n 2, octobre 1985, p. 23-25.

"Pomme Douly et les talons aiguille", Possibles, vol. X, nos 3-4, printemps-été 1986, p. 333-344.

"La marche pour la paix ", Mouvements, vol. III, n 6: "Guère de paix", juillet-août 1986 , p. $17-18$.

[sans titre], avec des illustrations de Pierre Grange, La Nouvelle Barre du jour, $\mathrm{n}^{\text {os }} 189-190$ : "Installations/fictions ", décembre 1986, n. p.

"La Passion selon Galatée" [extraits], Châtelaine, vol. XXVIII, $\mathrm{n}^{\circ} 2$, février 1987, p. 53-58.

"Pratiques d'écriture - notes", Possibles, vol. XI, no 3: "Langue culture", printemps-été 1987, p. 186-188.

"Vévé ", Trois, vol. III, nº 3, printemps-été 1988, p. 130-132.

"La Passion selon Galatée" [extraits], Canadian Literature, no 117, été 1988, p. 156-158.

"Aventures de Pomme Douly" [extraits], L'Actualité, vol. XIII, n 8, août 1988, p. 90 .

"Maude " [extraits], L'Actualité, vol. XIII, nº 8, août 1988, p. 90. 
"Conférence-fiction", Possibles, vol. XIII, no 4, automne 1988, p. 85-93.

"Aventures de Pomme Douly" [extraits], Nuit blanche, $\mathrm{n}^{\circ} 33$, septembre-novembre 1988, p. 11.

"Aventures de Pomme Douly " [extraits], Lettres québécoises, no 52, hiver 1988, p. 26-27.

"Maude" [extraits], Lettres québécoises, no 52, hiver 1988, p. 26-27.

"Pomme Douly et la répartition des tâches" [extraits], Possibles, vol. XII, n 1 , hiver 1988, p. 83-88.

"Un homme respecté" et "Couples " [extraits de Laura Laur et de La Passion selon Galatée], Lise Gauvin et Gaston Miron (dir.), Écrivains contemporains du Québec depuis 1950, Paris, Seghers, 1989, p. 285-290 [précédés d'une courte note biographique et d'une brève présentation de l'œuvre].

"La rupture des eaux", La Nouvelle Barre du jour, nos 218-219: "Femmes de lettres ", février-mars 1989, p. 113-116.

"Opinions", Nuit blanche, $\mathrm{n}^{\circ}$ 36: "Maudite langue", juin-août 1989, p. 48.

"Gémellaire" [extraits], Nicole Brossard et Lisette Girouard (dir.), Antbologie de la poésie de femmes au Québec, Montréal, Remue-Ménage, 1991, p. 222-223 [précédés d'une brève note biographiquel.

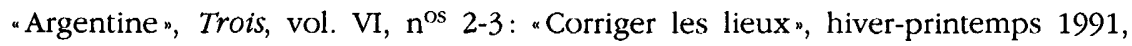
p. 177-178.

"Lire? ", Liberté, vol. XXXIII, n 1 (193): "Façons de lire ", février 1991, p. 40-43.

"L'obéissance" [extraits], L'Actualité, vol. XVI, n $17,1^{\mathrm{er}}$ novembre 1991, p. 139.

"Les majorités invisibles", Le Devoir, 4 juillet 1992, p. A1 et A4.

"Différé en direct ", Possibles, vol. XVI, n 4, automne 1992, p. 143-149.

"L'obéissance " [extraits], Femmes d'action, vol. XXII, n 2, novembre 1992, p. 41.

"Au sujet du risque", Mobius, n" 57 : "Entre le risque et la violence", automne 1993, p. 19-24.

[sans titre], en collaboration avec Chan Ky-Yut, Vie des arts, vol. XXXVIII, $\mathrm{n}^{\circ} 153$ : "Cahier artistes et écrivains", hiver 1993-1994, p. 25 du cahier.

"Livre de voûte ", Le Sabord, $\mathrm{n}^{\circ} 37$ : "Mémoire fleuve", printemps-été 1994, p. 1617.

"Les écrits de l'eau ", Possibles, vol. XVIII, no 1: "L'Artiste. (Auto)portraits", hiver 1994, p. 137-148.

\subsection{Commentaires}

\subsubsection{Journaux/magazines}

"C'est ma langue, je n'en ai pas d'autres", La Quinzaine Littëraire, n 436: "Écrire les langues françaises ", 16 au 31 mars 1985, p. 19.

"Federico Fellini: le don fellinien", 24 Images, no 71, février-mars 1994, p. 16-18. 


\subsubsection{Chronique "Ah..." dans La Gazette des femmes}

"De la sexualité : le dire ou ne pas le dire ", vol. III, n 1 , juin 1981, p. 27.

"Une fois qu'il faisait beau", vol. III, $\mathrm{n}^{\circ} 3$, septembre 1981, p. 27.

"Mais les yeux étaient ailleurs", vol. III, $\mathrm{n}^{\circ}$ 4, octobre 1981, p. 27.

[Sans titre], vol. III, n 5 , décembre 1981-janvier 1982, p. 27.

"J'ai dit oui", vol. III, $\mathrm{n}^{\circ}$ 6, février 1982, p. 27.

"Une petite bonne femme", vol. III, $\mathrm{n}^{\circ}$ 7, mars-avril 1982, p. 27.

"Rompre en beauté ", vol. IV, $\mathrm{n}^{\circ}$ 1, mai-juin 1982, p. 27.

"La sorcière me l'a dit n, vol. IV, no 2, juillet-août 1982, p. 27.

"J'aime les parades", vol. IV, n 3, septembre 1982, p. 27.

"Le suivi", vol. IV, $\mathrm{n}^{\circ} 4$, octobre 1982, p. 27.

"Des bras", vol. IV, n 5, novembre-décembre 1982, p. 27.

"Conseils pratiques pour vie peu commune", vol, IV, n ${ }^{\circ} 6$, janvier-février 1983, p. 27.

"Faire ses comptes", vol. IV, $\mathrm{n}^{\circ}$ 7, mars-avril 1983, p. 27.

"Un cancer", vol. V, n ${ }^{\circ} 1$, mai-juin 1983, p. 35.

"Adorables machos" ", vol. V., n' 2, juillet-août 1983, p. 35.

"All that jazz, simplement ", vol. V, n 3 , septembre-octobre 1983, p. 35.

"Des brasseuses d'affaires", vol. V, no 4, novembre-décembre 1983, p. 35.

"Rue Cases Nègres", vol. V, no 5, janvier-février 1984, p. 35.

"Une femme possédée ", vol. VI, no 1 , mai-juin 1984, p. 35.

"Fous rires", vol. VI, n 2 , juillet-août 1984, p. 35.

"L'Instabanque ", vol. VI, n 3 , septembre-octobre 1984, p. 35.

" Du tiraillage ", vol. VI, $\mathrm{n}^{\circ} 4$, novembre-décembre 1984, p. 35.

"Confidence pour confidence", vol. VI, $\mathrm{n}^{\circ} 5$, janvier-février 1985, p. 35.

"La déception", vol. VI, n 6, mars-avril 1985, p. 35.

"Votre beauté, Madame! ", vol. VII, n 1, mai-juin 1985, p. 35.

"Une toast ", vol. VII, nº 2, juillet-août 1985, p. 35.

"Une affaire normale ", vol. VII, no 4, novembre-décembre 1985, p. 35.

" "Tiens un cheveu!" ", vol. VII, no 6, mars-avril 1986, p. 35.

"Le siège $16 \mathrm{~A}$ ", vol. VIII, $\mathrm{n}^{\circ}$ 2, juillet-août 1986, p. 35.

"Pas de panique!", vol. VIII, no 4, novembre-décembre 1986, p. 35.

"Avez-vous déjà... ? Ah!... ", vol. vIII, nº 6, mars-avril 1987, p. 35.

"Ah!... Haute surveillance", vol. IX, $\mathrm{n}^{\circ}$ 1, mai-juin 1987, p. 35.

"Ah!... Tout de suite immédiatement ", vol. IX, n 2 , juillet-août 1987, p. 35.

"La guerre, madame, la guerre! n, vol. IX, nº 4, novembre-décembre 1987, p. 35. 
"Ah!... Est-ce qu'il neige? „, vol. IX, n 6, mars-avril 1988, p. 35.

"Ah!...Aux personnes concernées", vol. X, nº 2, juillet-août 1988, p. 35.

"Chauve ou poilue ", vol. $\mathrm{X}, \mathrm{n}^{\circ} 4$, novembre-décembre 1988, p. 35.

"Ah!... Mère ou Fille, telle n'est pas la question", vol. X, n 6, mars-avril 1989, p. 35.

"Ah!...Les postes clefs", vol. XI, n 2, juillet-août 1989, p. 35.

"Ah!... Carole six ans plus tard ", vol. XI, no 5 , janvier-février 1990, p. 35.

"Toujours-jamais ", vol. XII, no 1, mai-juin 1990, p. 35.

"Les garçons et les filles", vol. XII, n 3, septembre-octobre 1990, p. 35.

"Peser ou ne pas peser ", vol. XII, n 5, janvier-février 1991, p. 35.

\subsection{Disques}

GAUTHIER, Chrystian [paroles de Suzanne Jacob], Laisser jouer les enfants, SaintLaurent, Marche, distribué par Trans-Canada Musique Service, [1977].

Suzanne Jacob, avec la collaboration de Chrystian Gauthier et Jean Corriveau, les Productions du Clan Destin Inc., distribué par Solo Distribution, no SO 25514, 1979.

Filandere cantabile [poème avec disque compact], avec la collaboration de International Imaginaire Manifesto, Marc Moreau et Marion Moreau, Paris, Marval, 1990.

\subsection{Cinéma}

SAURIOL, Brigitte, Laura Laur, avec la collaboration de Nicole Robert (prod.), Lux Films, 110 min., Montréal, 1989.

\section{I.6. Radio}

L'Abitibi, un pays surréel [récit], Radio-Canada, 50 min., $1^{\text {er }}$ août 1979.

\subsection{Télévision}

Exercice pour une comparution [dramatique], Radio-Québec, 30 min., 8 avril 1979. Le Mur [dramatique], Radio-Québec, 30 min., 17 juin 1979.

\subsection{Théâtre}

Le rire de l'étrangère, présenté au Théâtre expérimental des femmes, 1983. 


\section{RÉCEPTION CRITIQUE ET ÉTUDES ${ }^{1}$}

\section{II.1. Sur l'auteure et son œuvre}

[ANONYME], "Suzanne Jacob", Réginald Hamel (dir.), Dictionnaire des auteurs de langue française en Amérique du Nord, Montréal, Fides, 1989, p. 707-708.

\section{II.2. Sur les œuvres}

\section{II.2.1. Les Aventures de Pomme Douly et Maude}

CHASSAY, Jean-François, "Du pire au meilleur ", Le Devoir, 14 mai 1988, p. D3.

FORTIN, Marie-Claude, "Suzanne Jacob. En avant, la musique", Voir, vol. 2, n 19 , 7 au 13 avril 1988, p. 9.

GAUDREAULT, André, "L'univers inquiétant de Mme Jacob", Le Nouvelliste, 11 juin 1988, p. 11A.

HÉBERT, Pierre, "Avez-vous vérifié votre gyrocompas récemment?", Lettres québécoises, $\mathrm{n}^{\circ}$ 52, hiver 1988-1989, p. 26-27.

MARCOTTE, Gilles, "La poésie du décousu main", L'Actualité, vol. XIII, $\mathrm{n}^{\circ} 8$, août 1988, p. 90.

MARTEL, Réginald, "Quand le maniérisme étouffe la manière... " La Presse, 14 mai 1988, p. K3.

PATERSON, Janet M., "Romans", University of Toronto Quarterly, vol. LIX, $\mathrm{n}^{\circ} 1$ : "Letters in Canada 1988", automne 1989, p. 21-32 [voir p. 29].

SAINT-MARTIN, Lori, "À l'ombre des jeunes femmes en fuite", Spirale, $\mathrm{n}^{\circ} 84$, décembre 1988, p. 19.

\section{II.2.2. "Les calmars"}

BEAUDOIN, Réjean, "Nouvelles du dernier siècle ", Liberté, vol. XXVIII, n 5 (167), octobre 1986, p. 102.

\section{II.2.3. Filandere Cantabile}

LÉVESQUE, Solange, “Filandere Cantabile", Jeu, n 62, mars 1992, p. 190-192.

\section{II.2.4. Flore Cocon}

BELLEMARE, Madeleine, "Notre choix. Flore Cocon de Suzanne Jacob", Nos Livres, vol. IX, août-septembre 1978, n. p. [voir rubrique $\mathrm{n}^{\circ} 285$ ].

FISCHMAN, Sheila, "Best-Selling Books Often Bad Reading", The Gazette, 18 mai 1979, p. 18 [à propos aussi de La Survie].

GAUVIN, Lise, "De la légende à l'histoire et à l'histoire de soi ", University of Toronto Quarterly, vol. XIVIII, no 4, été 1979, p. 336-337.

HAMEL, Marie-Andrée, "Flore Cocon mon amour... ", Le Livre d'ici, vol. III, $\mathrm{n}^{\circ} 40$, 7 décembre 1978, n. p.

1. Nous indiquons par un astérisque $\left(^{*}\right)$ les études de fond. 
HURTUBISE, Susane, "Flore Cocon, Suzanne Jacob", Le Bulletin Pantoute, $\mathrm{n}^{\circ} 1$, avril 1980 , p. 25.

LEMELIN, Serge, "Détecter la création chez les individus", Le Quotidien, 8 décembre 1979, p. 2-3.

MARTEL, Réginald, "Flore Cocon va de soin, La Presse, 3 juin 1978, p. D2.

MARTEL, Réginald, "Les bons romans de l'année 1977 ", La Presse, 30 décembre 1978 , p. C3.

MUNGER, Martin, "Flore Cocon", Focus, vol. I, n 12, juin 1978, p. 45.

OUELLETTE, Gabriel-Pierre, "Suzanne Jacob. Flore Cocon", Livres et Auteurs québécois 1978, Québec, Presses de l'Université Laval, 1979, p. 52-53.

OUELLETTE-MICHALSKA, Madeleine, "Flore Cocon", Châtelaine, vol. XIX, n 12 , décembre 1978, p. 12.

PARÉ, Yvon, "Un nouveau souffle dans l'édition, la littérature...", Le Quotidien, 24 février 1979, p. 7.

VANASSE, André, "Autour de six romans. 5- Flore Cocon de Suzanne Jacob", Lettres québécoises, $\mathrm{n}^{\circ} 11$, septembre 1978, p. 10-11.

WHITFIELD, Agnès, "Flore Cocon, roman de Suzanne Jacob", Dictionnaire des cuvres littéraires du Québec, tome VI, 1976-1980, Montréal, Fides, 1994, p. 340-341.

\section{II.2.5. Laura Laur}

* ANDERSON, M. Jean, "Mother, Mirror, Self: The "New" Writing of Suzanne Jacob", New Zealand Journal of French Studies, Palmerston North, NouvelleZélande, vol. IX, n 1, mai 1988, p. 113-124.

[ANONYME], "Prix littéraire Québec-Paris 1983", Québec-Hebdo, vol. VI, n 5 , 13 février 1984, p. 4.

—, "Prix Québec-Paris", Lettres québécoises, n³4, été 1984, p. 8.

_, "Prix du Gouverneur général", Lettres québécoises, $n^{\circ} 35$, automne 1984, p. 11.

BOURQUE, Paul-André, "Qui est Laura Laur? Qui est Le Valet de Plume?", Au masculin, vol. I, $\mathrm{n}^{\circ} 4$, octobre 1983, p. 21-22.

CARTANO, Tony, "Un galop d'essai ", Magazine littéraire, $\mathrm{n}^{\text {os }} 200-201$, novembre 1983, p. 108.

DARRAS, Jacques, "Laura Laur», Esprit, nº 83, novembre 1983, p. 167.

GAUDREAULT, André, "Laura Laur. Un talent exceptionnel ", Le Nouvelliste, 10 septembre 1983 , p. $24 \mathrm{~A}$.

GILBERT, Bernard, “Laura Laur , Intervention, $\mathrm{n}^{\text {os }} 22-23$, printemps 1984, p. 95.

GUAY, Gisèle, "N'en déplaise à Freud", Virus-Viva, vol. VI, nº 9, novembre 1983 , p. 10.

HAYWARD, Annette, "Laura Laur», Québec français, n 52, décembre 1983, p. 18. 
HOGUE, Jacqueline, "Laura Laur", Canadian Women Studies/Les Cabiers de la femme, vol. V, n 1 , automne 1983, p. 77-78.

* LAHAIE, Christiane, "Alice s'en va au cinéma, ou comment museler le roman féministe" [à propos de l'aclaptation cinématographique du roman], Recherches fëministes, vol. VII, $\mathrm{n}^{\circ} 2$ : "Représentations", 1994, p. 81-94.

LAMY, Suzanne et France THÉORET, "Les Québécois en France ", Spirale, no 38, novembre 1983 , p. 3.

LAURIER, Marie, "Suzanne Jacob, alias Laura Laur", Le Devoir, 16 novembre 1983, p. 15.

LISÉE, Jean-François, "Le prix Québec-Paris à Suzanne Jacob. Laura Laur fait la quasi-unanimité ", Le Droit, 31 janvier 1984, p. 14.

MARCOTTE, Gilles, "Madame Jacob a pondu une oasis "médinnequébec" ", L'Actualité, vol. VIII, $\mathrm{n}^{\circ} 10$, octobre 1983, p. 150.

MARTEL, Réginald, "Un roman de Suzanne Jacob. Laura Laur perdue, aperçue, secrète ", La Presse, 10 septembre 1983, p. D2.

-, "Suzanne Jacob. La passion et la distance", La Presse, 29 septembre 1984, p. E1 et E3.

MERIVALE, Patricia, "Autoportraits (Fernand Ouellette: Lucie ou un midi en novembre; Suzanne Jacob: Laura Laur)", Canadian Literature, $\mathrm{n}^{\circ} 109$, été 1986, p. 108-110.

MICHON, Jacques, "Romans", University of Toronto Quarterly, vol. LIII, n० 4, été 1984, p. 333-342 [voir p. 336].

MILOT, Louise, "Laura Laur de Suzanne Jacob ou comment nommer sans dire ", Lettres québécoises, $\mathrm{n}^{\circ} 32$, hiver 1983-84, p. 23-25.

MONTPLAISIR, Liane, "Laura Laur", Le Sabord, vol. II; n 1, février-mars 1984, p. 16 .

OUELLETTE-MICHALSKA, Madeleine, "Mais qui est donc Laura Laur?", Le Devoir, 10 septembre 1983, p. 17 et 32.

—, "Laura Laur", Châtelaine, vol. XXIV, n 12, décembre 1983, p. 24.

PELLERIN, Gilles, "Suzanne Jacob, 27 rue Jacob, 75006 Paris", Nuit blanche, $\mathrm{n}^{\circ} 10$, automne 1983, p. 11.

POULIN, Gabrielle, "Laura Laur de Suzanne Jacob. La fille-miroir ", Le Droit, $1^{\text {er }}$ octobre 1983 , p. 36.

[PRESSE CANADIENNE], "Suzanne Jacob, Prix Québec-Paris", La Presse, 31 janvier 1984, p. A12.

[PRESSE CANADIENNE], "Prix Québec-Paris à Suzanne Jacob", Le Soleil, 31 janvier 1984, p. B5.

ROLIN, Gabrielle, "Sois belle, mais tais-toi!", Matin de Paris, n $2020,1^{\mathrm{er}}$ septembre 1983, p. 29.

SAVIGNEAU, Josyane, "Voyage à travers les romans. À la recherche de Laura ", Le Monde, $\mathrm{n}^{\circ} 12005,2$ septembre 1983, p. 11. 
SIMARD, France, "Trois prix, trois réalités ", Le Droit, 29 septembre 1984, p. 23-24.

SOULIÉ, Jean-Paul, "Une femme sans permissions", La Presse, 26 novembre 1983, p. E2.

THÉORET, France, "Laura Laur de Suzanne Jacob", Spirale, no 38, novembre 1983, p. 3.

THÉRIAULT, Jacques, "Laura Laur, Livres d'ici, vol. IX, n 2, octobre 1983, p. 13.

TREMBLAY, Régis, "La vraie nature féroce de Laura Laur ", Le Soleil, 10 septembre 1983, p. E12.

-, "Face à Suzanne Jacob on n'a plus le choix", Le Soleil, 26 novembre 1983, p. C1.

VANASSE, André, "Les fous, les demeurés, les rêveurs ", Voix et Images, vol. IX, $\mathrm{n}^{\circ} 2$, hiver 1984 , p. 162-163.

\section{II.2.6 Life, After All}

FILIP, Ray, "A Dish of Bonbons", Books in Canada, vol. XVIII, n" 6, août-septembre 1989, p. 34.

\section{I1.2.7. L'Obéissance}

BASILE, Jean, "La désobéissance ou la mort ", Le Devoir, 14 septembre 1991, p. C3.

BEAUSOLEIL, Jean-Marc, "Le silence qui tue ", Continuum, 25 novembre 1991, p. 14.

CARRIER, Anne, "Des histoires gigognes pour essayer que quelque chose soit dit ", Québec français, no 85 , printemps 1992, p. 85.

CLOUTIER, Guy, "Les douleurs d'une enfance bafouée ", Magazine littéraire, $n^{\circ} 295$, janvier 1992, p. 62.

DOLBEC, Michel, "Louis Hamelin et Suzanne Jacob dans la mêlée parisienne ", La Presse, 9 octobre 1991, p. D9.

ÉMOND, Ariane, "Quand parent rime avec tyran", Elle Québec, no 26, octobre 1991, p. 56-58.

FORTIN, Marie-Claude, "L'Obéissance. Une âme à la mère ", Voir, vol. V, n 40, 29 août au 4 septembre 1991, p. 27.

MARCOTTE, Gilles, "Père et mère tu honoreras...", L'Actualité, vol. XVI, no 17 , $1^{\mathrm{er}}$ novembre 1991, p. 139.

MARTEL, Réginald, "Histoire d'un fait divers", La Presse, 22 septembre 1991, p. C3. MEUDAL, Gérard, “... Sauf maman ”, Libération, n 3218, 26 septembre 1991, p. 25.

POULIN, Andrée, "L'Obéissance. La noirceur dans un rapport mère/fille ", Le Droit, 7 septembre 1991, p. A11.

* SAINT-MARTIN, Lori, "L’amour et la rivière: L'Obéissance de Suzanne Jacob", Gabrielle Pascal (dir.), Le roman québécois au féminin (1980-1995), Montréal, Triptyque, p. 161-174. 
ROY, Monique, "Suzanne Jacob et L'Obéissance", Châtelaine, vol. XXXII, no 11 , novembre 1991, p. 26.

V.-HAMEL, Doris, L'Obéissance: un livre émouvant, passionné ", Le Nouvelliste, 16 janvier 1992, p. 18.

\section{II.2.8. La Passion selon Galatée}

BEAUDET, Marie-Andrée, "La Passion selon Galatée", Québec français, n”66, mai 1987, p. 16.

BEAUDOIN, Réjean, "La Passion cuisinée", Liberté, vol. XXIX, n 171, juin 1987, p. 90-94.

DEMALSY, Annick, "La Passion selon Galatée. Qui trouve cherche", Continuum, semaine du 30 mars 1987, p. 20.

EDDIE, Christine, "La Passion selon Galatée", Nuit blanche, $\mathrm{n}^{\circ} 28$, mai-juin 1987 , p. 5 .

GAUDREAULT, André, "Laura Laur a recollé ses morceaux ", Le Nouvelliste, 17 janvier 1987, p. 13A.

LAURIN, Michel, "Suzanne Jacob. La Passion selon Galatée", Nos Livres, vol. XVIII, avril 1987, p. 30-32.

MARCOTTE, Gilles, "God, Pigue et maringouins", L'Actualité, vol. XII, n 3, mars 1987, p. 145.

MARTEL, Réginald, "Une passion en forme de puzzle", La Presse, 7 février 1987, p. E1 et E3.

MILOT, Louise, "Une passion d'auteure ", Lettres québécoises, n 46, été 1987, p. 21-23.

OUELLETTE-MICHALSKA, Madeleine, "Pour l'amour d'un puzzle ", Le Devoir, 14 mars 1987, p. D3.

POTVIN, Elisabeth, "Passion", Canadian Literature, no 117, êté 1988, p. 156-158.

RENAUD, André, "Une tornade d'imagination*, Le Droit, 22 août 1987, p. 33.

ROYER, Jean, *Les grands boulevards intérieurs ", Le Devoir, 31 janvier 1987, p. B1 et $\mathrm{B} 5$.

RUDEL-TESSIER, Danielle, "Un roman en "ronron" ", Le Matin, 6 février 1987, p. W16.

SAINT-MARTIN, Lori, "Un virage douloureux", Spirale, no 70, mai 1987, p. 11.

VOISARD, Anne-Marie, "Dans La Passion selon Galatée Jacob sait garder le lecteur en haleine", Le Soleil, 24 janvier 1987, p. C7.

\subsubsection{Poèmes 1. Gémellaires. Le Chemin de Damas}

BEAULIEU, Michel, "Les premiers pas poétiques du Biocreux ", Le Livre d'ici, vol. XVI, n 17, 28 janvier 1981, n. p.

BONENFANT, Joseph, "Notes sur la poésie", Voix et Images, vol. VI, $\mathrm{n}^{\circ} 3$, printemps 1981, p. 481-485. 
COTNOIR, Louise, "Paroles et petits blasphèmes", Spirale, no 16, février 1981, p. 9-10.

D'ALFONSO, Antonio, "Poèmes 1. Gémellaires. Le Chemin de Damas", Nos Livres, vol. XII, juin-juillet 1981, n. p. [voir rubrique $\mathrm{n}^{\circ} 290$ ].

DUPRÉ, Louise, "Suzanne Jacob, Gémellaires. Le Chemin de Damas. Francine Péotti, Passeport blasphématoire pour l'biver québécois", Livres et Auteurs québécois 1980, Québec, Presses de l'Université Laval, 1981, p. 109-111.

GAULIN, André, "Suzanne Jacob. Poèmes 1", Québec français, n 41, mars 1981, p. 15.

PERRON, Gilles, "Poèmes 1, recueil de poésies de Suzanne Jacob", Dictionnaire des cuvres littéraires du Québec, tome VI, 1976-1980, Montréal, Fides, 1994, p. 647-648.

ROYER, Jean, "Les chemins de la tendresse ", Le Devoir, 20 décembre 1980, p. 18.

\section{II.2.10. La Survie}

BEAULIEU, Benoit, "Suzanne Jacob. La Survie", Livres et Auteurs québécois 1979, Québec, Presses de l'Université Laval, 1980, p. 50-51.

BOIVIN, Aurélien, "La Survie», Québec français, n 38, mai 1980, p. 12.

CLOUTIER, Guy, [préface à l'édition de 1989], Montréal, BQ, coll. "Littérature", 1989 , p. 7-11.

CORRIVEAU, Hugues, "Le Biocreux où l'écriture se livre ", La Nouvelle Barre du jour, no 82 , octobre 1979 , p. 84-95.

DANSEREAU, Estelle, "La séduction du lecteur dans les contes québécois des années 1970 ", Études canadiennes, n 28,1990 , p. 25-36.

FISCHMAN, Sheila, "Best-Selling Books Often Bad Reading ", The Gazette, 18 mai 1979, p. 18 [à propos aussi de Flore Cocon].

GAUVIN, Lise, "Les maisons d'édition et la fiction au Québec ", University of Toronto Quarterly, vol. XIIX, no 4, été 1980, p. 336-347.

LEMELIN, Serge, "Détecter la création chez les individus", Le Quotidien, 8 décembre 1979 , p. 2-3.

MARTEL, Réginald, "Sur le fil très ténu d'une humeur simple ", La Presse, 3 mars 1979, p. D3.

MELANÇON, Robert, "Un nouvel éditeur: Le Biocreux", Le Devoir, 17 février 1979, p. 21.

- "Poùr un bilan de la saison littéraire 78-79", Le Devoir, 7 juillet 1979, p. 11.

MUNGER, Martin, "La Survie", Focus, vol. II, n²3, juin 1979, p. 52.

OUELLETTE-MICHALSKA, Madeleine, "Des voix chaudes venues de froids pays ", Châtelaine, vol. XX, $\mathrm{n}^{\circ} 6$, juin 1979, p. 6.

PARÉ, Yvon, «Un nouveau souffle dans l'édition, la littérature... ", Le Quotidien, 24 février 1979 , p. 7. 
p. 8.

PERKES, Carolyn, "La Survie, recueil de nouvelles de Suzanne Jacob", Dictionnaire des cuvres littéraires du Québec, tome VI, 1976-1980, Montréal, Fides, 1994, p. 772-773.

* POISSANT, Renée, "Prétextes pour une renaissance ", mémoire de maîtrise ès arts, Département d'études littéraires, Université du Québec à Montréal, 1982.

ROCHON, Sylvaine, "La Survie. Dix-neuf nouvelles signées Suzanne Jacob", Le Livre d'ici, vol IV, $\mathrm{n}^{\circ} 24,21$ mars 1979, n. p.

VIGEANT, Louise, "La Survie", Nos.Livres, vol. X, juin-juillet 1979, n. p. [voir rubrique $\left.n^{\circ} 220\right]$.

\section{II.3. Sur les spectacles}

BEAULIEU, Pierre, "Suzanne Jacob rit et fait rire", La Presse, 28 avril 1979, p. E11.

' , "Suzanne Jacob nous oblige à faire un petit effort ", La Presse, 14 novembre 1980, p. C7.

CAUCHON, Paul, "Le beau risque de la chanteuse", Le Devoir, $1^{\text {er }}$ février' 1986, p. 21 et 28.

CHAREST, Luc, "L'art du spectacle s'affirme", Vie des arts, vol. XXVII, no 110, mars-avril-mai 1983, p. 65 [à propos de la pièce Le Rire de l'étrangère].

GAUDREAULT, Léonce, "Suzanne Jacob: pour l'étonnement ", Le Soleil, 17 avril 1986, p. B10.

LAVOIE, Denis, "Faire parler le corps », La Presse, 25 janvier 1986, p. E1 et E5. p. B4.

LEMERY, Marthe, "Suzanne Jacob à la Maison du Citoyen. La musique qui remue les entrailles ", Le Droit, 9 décembre 1981, p. 24.

—_ "Rejetée par l'industrie du spectacle au Québec, Suzanne Jacob s'en va en France ", Le Droit, 11 septembre 1981, p. 14.

MCMURRAY, Line, "Une étrangère, un rire ", Spirale, $\mathrm{n}^{\circ}$ 32, mars 1983, p. 13 [à propos de la pièce Le Rire de l'étrangère].

PETROWSKI, Nathalie, "Suzanne Jacob prend la vie du bon côté, Canadian Composer/Compositeur canadien, $\mathrm{n}^{\circ}$ 142, juin 1979, p. 4-7.

- "Suzanne Jacob au Conventum: un imaginaire tendre et cynique ", Le Devoir, 14 novembre 1980, p. 16.

ROBERGE, Françoy, "D'emblée parmi les grands de la chanson ", Le Devoir, 26 avril 1979, p. 22.

TREMBLAY, Régis, "Tout arrive à Suzanne Jacob ", Le Soleil, 17 janvier 1981, p. F1. p. D8. 


\section{ENTRETIENS}

ALIX, Yves, "Suzanne Jacob, une chanson en exploration", Mouvements, vol. III, $\mathrm{n}^{\circ} 4$, mars-avril 1986, p. 52-53 [accompagné d’une critique du spectacle Autre].

BEAUlIEU, Pierre, "Un moment dans la vie de Suzanne Jacol)", La Presse, 16 décembre 1978, p. D8.

La Presse, 15 novembre 1980, p. C1 et C8.

BERNIER, Conrad, "Suzanne Jacob: "J'écris pour en finir avec les interdits et les cloisons" ", La Presse, 27 mai 1978, p. D2.

CARRIER, Anne, "Qui est Suzanne Jacob?", Québec français, n" 85, printemps 1992, p. 82-84 [accompagné d'une esquisse biographique].

CUSSON, Normand, "Suzanne Jacob ", Clin d'xeil, n³, novembre 1980, p. 6.

GUAY, Hervé, "Avec un crayon Mirado jaune B ", Le Devoir, 9 novembre 1991, p. 16-17.

FORTIN, Marie-Claude, "Suzanne Jacob: celle qui voit ", Voir, vol. V, no 52,21 au 27 novembre 1991, p. 22.

HAMEL, Marie-Andrée, "Ce que je lis... Suzanne Jacob", Le Livre d'ici, vol. V, $\mathrm{n}^{\circ} 6$, 14 novembre 1979 , n. p.

LAFUSTE, France, "De la chanson au roman, aller-retour ", Le Devoir, 7 mai 1988, p. D1.

LAURIER, Andrée, "La rentrée de Suzanne Jacob", Canadian Composer/Compositeur canadien, $\mathrm{n}^{\circ}$ 212, juin-juillet 1986, p. 5-9 [à propos du spectacle Autre].

LAURIER, Marie, "Suzanne Jacob, alias Laura Laur", Le Devoir, 16 novembre 1983, p. 15.

LAURIN, Michel, "Interview", Nos livres, octobre 1987, p. 4-6 là propos de Laura Laur.

MARTIN, Jean-Guy, "En votant non, les Québécois ont rejeté Vigneault, Miron, Leclerc et les autres" n, Le Journal de Montréal, 13 septembre 1980, p. 5.

PEDNEAULT, Hélène, "Suzanne Jacob: lettres de Paris", La Vie en rose, $\mathrm{n}^{\circ} 10$, mars 1983, p. 62-63.

PELLETIER, Denise, "Suzanne Jacob. Un lent chemin vers la lumière", ProgrèsDimanche, 25 février 1979, p. 56.

[PRESSE CANADIENNE], "Laura Laur ne se suicide-t-elle pas?", La Presse, 20 décembre 1983, p. A16.

ROBERGE, Pierre, "Suzanne Jacob et son dernier roman Laura Laur: "J'aime laisser l'espace au lecteur" ", Le Droit, 6 décembre 1983, p. 48.

_-, "Suzanne Jacob: "Laisser de l'espace au lecteur pour qu'il puisse imaginer" ", La Tribune, 17 décembre 1983, p. E5.

ROY, Pierrette, "Suzanne Jacob en chanson ou une authenticité retrouvée ", La Tribune, 25 août 1979, p. 33. 
ROYER, Jean, "Suzanne Jacob. Le corps traversé des mots ", Le Devoir, 8 novembre 1980 , p. 21 [reproduit dans Écrivains contemporains. Entretiens 2: 19771980, Montréal, l'Hexagone, 1983, p. 113-117; aussi dans Romanciers québécois. Entretiens. Essais, Montréal, l'Hexagone, 1991, p. 157-162].

"Suzanne Jacob. Comment passer de l'image à l'acte?", Écrivains contemporains. Entretiens 5: 1986-1989, Montréal, l'Hexagone, 1989, p. 143-148.

SAINT-JACQUES, Marie, "Une femme qui dérange: Laura Laur de Suzanne Jacob ", La Gazette des femmes, vol. V, n 4, novembre-décembre 1983, p. 2425.

SAMSON, Jacques, "Suzanne Jacob, en pleine possession de son devenir ", Le Soleil, 3 mai 1980 , p. C4.

THIBAULT, Michèle, "Il faut démolir les murs", Perspectives, vol. XXI, n 41,13 octobre 1979, p. 8 et 10 .

VOISARD, Anne-Marie, "L'art de se dédoubler ", Le Soleil, 7 février 1987, p. D1 et D4 [à propos de La Passion selon Galatée]. 